\title{
Environmental perturbation in the southern Tethys across the Paleocene/Eocene boundary (Dababiya, Egypt): Foraminiferal and clay mineral records
}

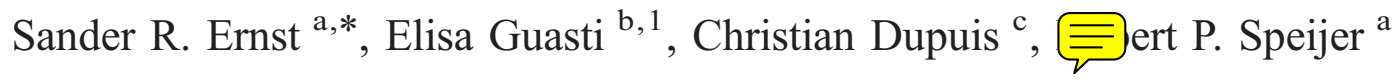 \\ a Department of Geography and Geology, K.U. Leuven, Celestijnenlaan 200E, B-3001, Belgium \\ b Department of Geosciences, Bremen University, P.O. Box 330 440, 28334 Bremen, Germany \\ ${ }^{\mathrm{c}}$ Faculté Polytechnique de Mons, rue de Houdain 9, B-7000, Mons, Belgium
}

Received 1 September 2005; received in revised form 2 March 2006; accepted 7 March 2006

\begin{abstract}
Foraminiferal and clay mineral records were studied in the upper Paleocene to lower Eocene Dababiya section (Egypt). This section hosts the GSSP for the Paleocene/Eocene boundary and as such provides an expanded and relatively continuous record across the Paleocene/Eocene Thermal Maximum (PETM). Deposition of illite-smectite clay minerals is interpreted as a result of warm and arid conditions in the southern Tethys during the latest Paleocene. Benthic foraminiferal assemblages are indicative of seasonal variation of oxygen and food levels at the seafloor. A sea-level fall occurred in the latest Paleocene, followed by a rise in the earliest Eocene. Foraminiferal diversity and densities decreased strongly at the P/E boundary, coinciding with the level of global extinction of benthic foraminifera (BEE) and start of the Carbon Isotope Excursion (CIE) and PETM. In the lower CIE, the seafloor of the stratified basin remained (nearly) permanently anoxic and azoic. A sudden increase in mixed clay minerals (kaolinite and others) suggests that warm and perennial humid conditions prevailed on the continent. High levels of TOC and phosphathic concretions in the middle CIE are evidence for increased organic fluxes to the sea floor, related to upwelling and to augmented continental runoff. Low densities of opportunistic taxa appeared, indicating occasional ephemeral oxygenation and repopulation of the benthic environment. The planktic community diversified, although conditions remained poor for deep-dwelling taxa. An increase in illite-smectite dominated clay association is considered to mark the return of a seasonal signature on climatic conditions. During the late CIE environmental conditions changed to seasonally fluctuating mesotrophic conditions and diverse and rich benthic and planktic foraminiferal communities developed. Post-CIE planktic faunas consisted of both deep and shallow-dwelling taxa and buliminid-dominated benthic assemblages reflect fluctuating mesotrophic conditions.

The frequent environmental perturbations during the CIE/PETM at Dababiya provided a rather specialized group of foraminiferal taxa (i.e., Anomalinoides aegyptiacus) the opportunity to repopulate, survive and subsequently dominate by a hypothesized capacity to switch to an alternative life strategy (population dynamics, habitat shift) or different metabolic pathway. The faunal record of Dababiya provides insight into the cause and development of the BEE: various severe global changes during the PETM (e.g., ocean circulation, $\mathrm{CaCO}_{3}$-dissolution, productivity and temperature changes) disturbed a wide range of environments on a geologically brief timescale, explaining together the geographically and temporally variable character of the
\end{abstract}

* Corresponding author. Current address: Faculty of Geosciences, Department of Stratigraphy and Paleontology, Utrecht University, Budapestlaan 4, 3584 CD Utrecht, The Netherlands. Tel.: +31 30 2535171; fax: +31 30253.

E-mail address: srernst@geo.uu.nl (S.R. Ernst).

${ }^{1}$ Current address: Stratigraphy Department, Fugro Robertson Ltd Llandudno LL30 1SA, UK. 